\begin{tabular}{|c|c|}
\hline & $\begin{array}{l}\text { International Journal of Trend in Scientific } \\
\text { Research and Development (IJTSRD) }\end{array}$ \\
\hline 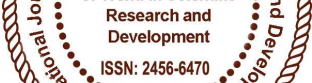 & International Open Access Journal \\
\hline 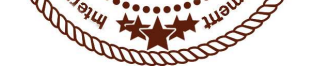 & ISSN No: 2456 - 6470 | www.ijtsrd.com | Volume - 2 | Issue - 2 \\
\hline
\end{tabular}

\title{
An Experimental Analysis of Turning Operation in SAE E52100 Alloy
}

\author{
Rajamurthy. G, Rakesh.V, Ramesh.P, Sundar.C \\ UG Students, K. Ramakrishnan College of Technology, Trichy, Tamil Nadu, India
}

\section{ABSTRACT}

Turning is a one type of machining process typically a non-rotary tool bit by moving linearly while the work piece rotates. It is used to create a cylindrical part by cutting unwanted materials. Today computer numerical control can be used, better known as CNC. Axles and shafts can be manufactured by turning process.by the different machining parameters such as feed, depth of cut and speed production rate and the quality of the product can also increase. Optical parameters play an important role in increase the productivity, reducing lead time with desired product quality at minimum cost. The experiments were conducted with Taguchi's L 9 mixed orthogonal array. EN 31 alloy steel can be machined by the Noncoated insert in computer numerical control lathe(CNC). By using the optical parameters individually for minimum surface roughness and maximum material removal rate(MRR) were found using taguchi analysis.

\section{INTRODUCTION}

Supriya sahu[1] Is attempt to solve the sustainability issues in turning process. This process was optimized from power consumption point of view. In this process surface roughness, material removal rate and energy consumption were considered as sustainability factors. The effect of surface roughness and material removal rate were analyzed. Meenu Gupta [2] is investigating the influence of cutting parameters on longitudinal turning of high silicon alloy using PCO tools. The result will be analyzed on machining parameters such as geometric and cutting forces and there effects. Amol Thakare[3] is analyzed the input parameters such as cutting speed, feed and nose radius. By using the classical method the output variables such as main cutting force and feed force can be evaluate. Robert kwalcz [4] is analyze input parameters such ad cutting speed, feed rate and depth of cut. By the taguchi method the output values can be calculated such as tool wear surface roughness, tool geometry and cutting fluid. Thus the result will be the machining of hard materials at higher speeds and lower feeds is improved by using coated tools. Sunil dambhare[5] analyzed the machining parameters by the single crystal diamond tools and poly crystal diamond tool. By using the taguchi method the Result is analyzed such as the surface roughness increases as feed rate increases. It is found that feed rate is more significant factor followed by depth of cut and cutting speed. Rosa [6] is investigate steady state temperature distribution on non-coated carbide tool by the finite analysis method. Cutting tool temperatures are strongly influenced due to edge deformation and the progressive development of flank land.

\section{Experimental Set Up}

The specimen material is in cylindrical form which has $100 \mathrm{~mm}$ length and $20 \mathrm{~mm}$ diameter with the help of non-coated insert. For this method L9 orthogonal array can be used. For the present experiment work the two process parameters at three levels and one parameter at two levels have been decided. Computer Numerical Controlled lathe with a variable speed of 50 to $50,000 \mathrm{rpm}$ and a power rating of AC motor can be preferred and is shown in figure 1 . 


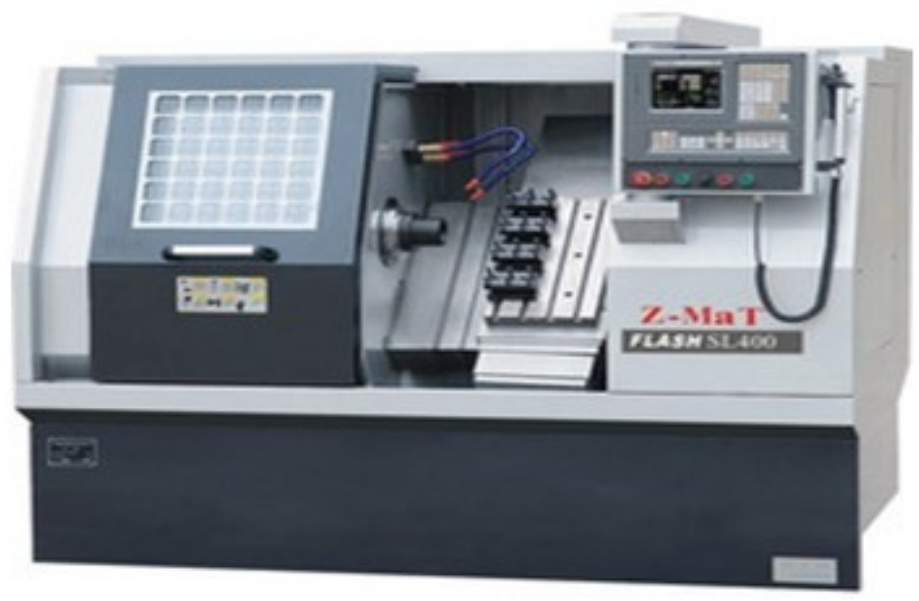

Figure 1- Computer Numerical Controlled Lathe

\subsection{Work piece Material - EN 31 Alloy Steel}

Cylindrical bars of $20 \mathrm{~mm}$ diameter and $100 \mathrm{~mm}$ long were used for this experimentation process. The chemical composition of the material is Carbon$0.101 \%$, Silicon- $0.30 \%$, Sulphur- $0.24 \%$, Chromium$0.76 \%$, Phosphorous- $0.028 \%$, Manganese- $0.78 \%$.

\subsection{Process variables and their limits}

In this experimental study, spindle speed, feed and depth of cut have been considered in this process. The process variables and their limits were shown in table 1.

Table 1 - Process variables and their limits

\begin{tabular}{|l|c|r|c|}
\hline \multicolumn{1}{|c|}{ Parameters } & Level 1 & Level 2 & Level 3 \\
\hline $\begin{array}{l}\text { Cutting } \\
\text { speed(m/min) }\end{array}$ & 1250 & 1350 & 1450 \\
\hline Feed(mm/rev) & 0.25 & 0.30 & 0.35 \\
\hline $\begin{array}{l}\text { Depth of cut } \\
\text { (mm) }\end{array}$ & 0.5 & 0.75 & 1 \\
\hline
\end{tabular}

\subsection{Selection of experimental designs}

Based on Taguchi's orthogonal array design L9 array can be selected and it is mentioned in the table 2 . The experiments were designed with the help of design of experiments [7 to 10].
Table 2 - Process variables and their limits

\begin{tabular}{|l|l|l|l|}
\hline Experiment no & Speed & Feed & Depth of cut \\
\hline $\mathbf{1}$ & 1250 & 0.25 & 0.5 \\
\hline $\mathbf{2}$ & 1350 & 0.3 & 0.5 \\
\hline $\mathbf{3}$ & 1450 & 0.35 & 0.5 \\
\hline $\mathbf{4}$ & 1350 & 0.25 & 0.75 \\
\hline $\mathbf{5}$ & 1450 & 0.3 & 0.75 \\
\hline $\mathbf{6}$ & 1250 & 0.35 & 0.75 \\
\hline $\mathbf{7}$ & 1450 & 0.25 & 1 \\
\hline $\mathbf{8}$ & 1250 & 0.3 & 1 \\
\hline $\mathbf{9}$ & 1350 & 0.35 & 1 \\
\hline
\end{tabular}

\subsection{Material Removal Rate}

Initial and final weights of work piece were noted. Machining time was also recorded. Following equation is used to determine the response Material Removal Rate (MRR).

$\mathrm{MRR}=$ (Initial weight - final weight $) /($ density $\times$ machining time)

\subsection{Surface Roughness}

Surface roughness generally can be described as the geometric features of the surface. The roughness measurement, in the transverse direction, on the work pieces has been repeated three times and average of three measurements of surface roughness parameter values has been noted in table.

\section{Analysis of results}

The Material Removal Rate and Surface Roughness were shown in table 3 . The analysis were carried out in Taguchi optimization method [11 to 18] .

\section{Table 3- Material Removal Rate and Surface Roughness}

\begin{tabular}{|l|l|l|}
\hline S.NO & MRR & SR $(\boldsymbol{\mu m})$ \\
\hline $\mathbf{1}$ & 42.46 & 1.26 \\
\hline $\mathbf{2}$ & 50.95 & 1.75 \\
\hline $\mathbf{3}$ & 56.61 & 1.55 \\
\hline $\mathbf{4}$ & 69.48 & 1.67 \\
\hline $\mathbf{5}$ & 84.92 & 1.66 \\
\hline $\mathbf{6}$ & 84.92 & 1.99 \\
\hline $\mathbf{7}$ & 101.91 & 1.42 \\
\hline $\mathbf{8}$ & 101.91 & 1.64 \\
\hline $\mathbf{9}$ & 113.23 & 1.53 \\
\hline
\end{tabular}




\section{Material removal rate analysis}

$\mathrm{SN}$ ratios are used to determine the optical design conditions to obtain the optimum material removal rate. The plot below represents the main effect plot of SN ratio for the MRR

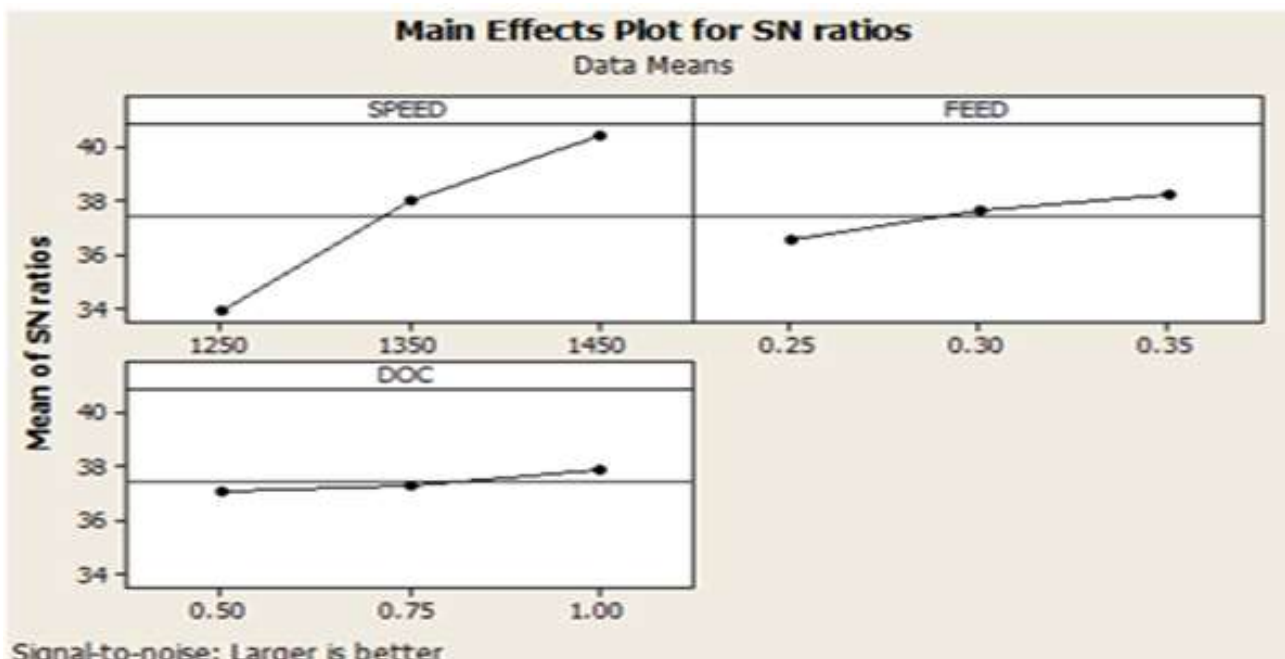

Figure 2 - Main Effects plots of SN ratio for MRR in Non- coated insert

According to this main effect plot of SN ratio (figure 2), the optical conditions for maximum MRR in noncoated insert.

1. Cutting speed at $1450 \mathrm{~m} / \mathrm{min}($ level 3$)$.

2. Feed rate at $0.35 \mathrm{~mm} / \mathrm{rev}$ (level 3).

3. Depth of cut $0.45 \mathrm{~mm}($ level 1$)$

\subsection{Surface Roughness Analysis}

The main effects plots are used to determine the optimal deign conditions to obtain the optimum surface roughness. The plot shows the main effect plot of SN ratio for the surface roughness. According to this main effect plot of SN ratio (figure 3), the optical conditions for minimum surface roughness are:

1. Cutting speed at $1350 \mathrm{~m} / \mathrm{min}$ (level 1).

2. Feed rate at $0.35 \mathrm{~mm} / \mathrm{rev}$ (level 2).

3. Depth of cut at $0.75 \mathrm{~mm}$ (level 2).

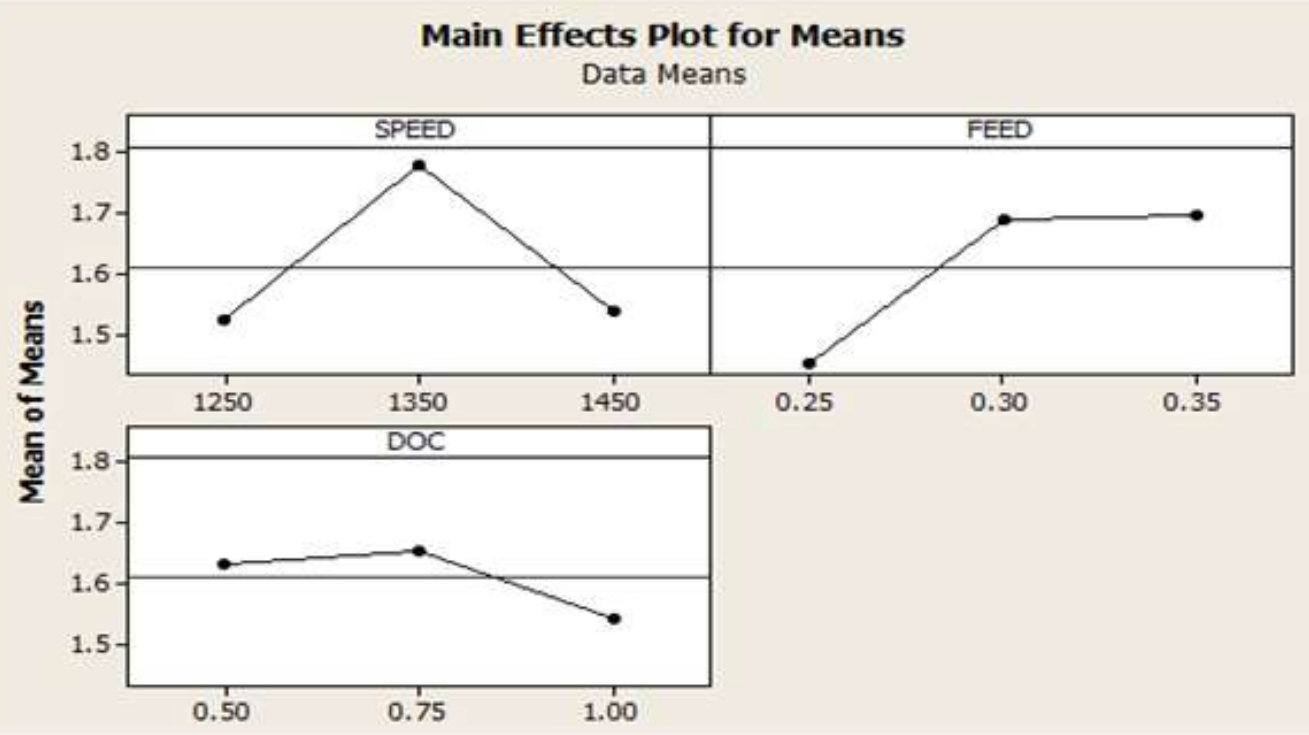

Figure 3 - Main effect plots of SN ratio for SR in Non-coated insert 
International Journal of Trend in Scientific Research and Development (IJTSRD) ISSN: 2456-6470

\section{Conclusion}

The experiments were conducted on the basis of input parameters and their corresponding levels, L9 orthogonal array was selected for this design of experiments.

1. Experimentation was carried out with non-coated insert and the material removal rate and surface roughness was experimentally verified based on the input

2. The best feasible combination of parameters was identified using the signal to noise ratio individually for both MRR and SR.

3. The feasible properties of MRR are

i. Cutting speed at $1450 \mathrm{~m} / \mathrm{min}$ (level 3 ).

ii. Feed rate at $0.25 \mathrm{~mm} / \mathrm{rev}$ (level 1).

iii. Depth of cut at $1 \mathrm{~mm}$ (level 3).

4. The feasible properties of SR are

i. Cutting speed at $1350 \mathrm{~m} / \mathrm{min}$ (level 3).

ii. Feed rate at $0.35 \mathrm{~mm} / \mathrm{rev}$ (level 1).

iii. Depth of cut at $0.75 \mathrm{~mm}$ (level 1).

\section{References}

1) Masao Murakana, Supriya sahu (2015) Application of brazed diamond film as interest for turning aluminum alloys'.

2) Meenu Gupta, Surinder Kumar,(2015 ),'Investigation of surface roughness and MRR for turning of UD-GFRP using PCA and taguchi method'.

3) Amol thakare , Shivakumar Raman (2015), Observations of tool-chip boundary conditions in turning of aluminium alloys' .

4) Robert kowalcz (2015), 'Development of threedimensional finite element model to calculate the turning processing parameters in turning operations'.

5) Sunil Dambhare, Samir Deshmukh, Atul Borade,(2015), 'Sustainability issues in turning process: a study in Indian machining industry .

6) T.fraga oa selva, R.B. Soares ,A.M.P Jesus, P.A.R.Rosa (2015) 'Simulation studies of turning of aluminum cast alloy using ped tools.

7) Radhakrishnan.K, Godwin Antony.K, Rajaguru.K, Dinesh.S, Experimental Investigation on Machining of Aluminium Metal Matrix using Electrical Discharge Machining, Advances in
Natural and Applied Sciences, Vol. 11. No 7, pp.no 809-816.

8) Dinesh S, Godwin Antony A, K.Rajaguru, V.Vijayan," Investigation and Prediction of Material Removal Rate and Surface Roughness in CNC Turning of En24 Alloy Steel", Mechanics and Mechanical Engineering 20 (4), 451-466.

9) Dinesh S, Godwin Antony A, K.Rajaguru, V.Vijayan," Experimental Investigation and Optimization of Material Removal Rate and Surface Roughness in Centerless grinding of Magnesium Alloy using Grey Relational Analysis", Mechanics and Mechanical Engineering, Vol 21, No 1 (2017), pp.no 17-28.

10) Kannan.S, Suresh Kumar.B, Baskar. N, Varatharajalu.M, (2015), Investigation on optimum cutting condition in face milling of copper with HSS cutter using response surface methodology and genetic algorithm', International Journal of Applied Engineering Research, ISSN 0973-4562 Vol. 10 No.57, 243-248.

11) Deepan Bharthi Kannan.T,Rajesh Kannan.G, Suresh Kumar. B, Baskar.N (2014),' Application of Artificial Neural Network for Machining parameters optimization in drilling operation', Procedia Material sciences, Vol. 5, 2242-2249.

12) B. Suresh kumar, V. Vijayan, N. Baskar (2016), 'Comparison of coated and uncoated carbide drill bits for drilling titanium grade 2 material', Mechanika, Vol. 22 no 6, 571-576.

13) Godwin Antony A, Aravind S, Dinesh S, K.Rajaguru, V.Vijayan," Analysis and Optimization of Performance Parameters in Computerized IC Engine Using Diesel Blended with Linseed Oil and Leishmaan's Solution", Mechanics and Mechanical Engineering, Vol 21 issue 2, pp.no 193-205.

14) Dinesh S, Godwin Antony A, K.Rajaguru, V.Vijayan," Experimental Investigation and Optimization of Machining Parameters in CNC Turning Operation of Duplex Stainless Steel", Asian Journal of Research in Social Sciences and Humanities, Vol. 6, No. 10, October 2016, pp. 179-195.

15) Dinesh S, Prabhakaran M, Godwin Antony A, K.Rajaguru, V.Vijayan,"Investigation and Optimization of Machining Parameters in Processing AISI 4340 Alloy Steel with Electric Discharge Machining", International Journal of 
Pure and Applied Mathematics, Vol 117 No. 16 2017, 385-391.

16) Dinesh S, Godwin Antony A, K.Rajaguru, V.Vijayan, "Comprehensive Analysis of Wire Electric Discharge Machining Process in Machining High Chromium High Carbon Steel”, International Journal of Mechanical and Production Engineering Research and Development Vol. 8, No 1, Feb 2018, 65-74.

17) Suresh kumar. B, Baskar. N, ' Integration of fuzzy logic with response surface methodology for thrust force and surface roughness modeling of drilling on titanium alloy', International Journal of Advanced Manufacturing Technology 65 (2013) 1501-1514.

18) Kannan.S, Varatharajalu.M, Baskar.N, Suresh Kumar. B, Modeling and optimization of face milling parameters on brass component using response surface methodology and genetic algorithm, International Journal of Applied Engineering Research, Vol. 10 No.76 (2015) 219 $-224$.

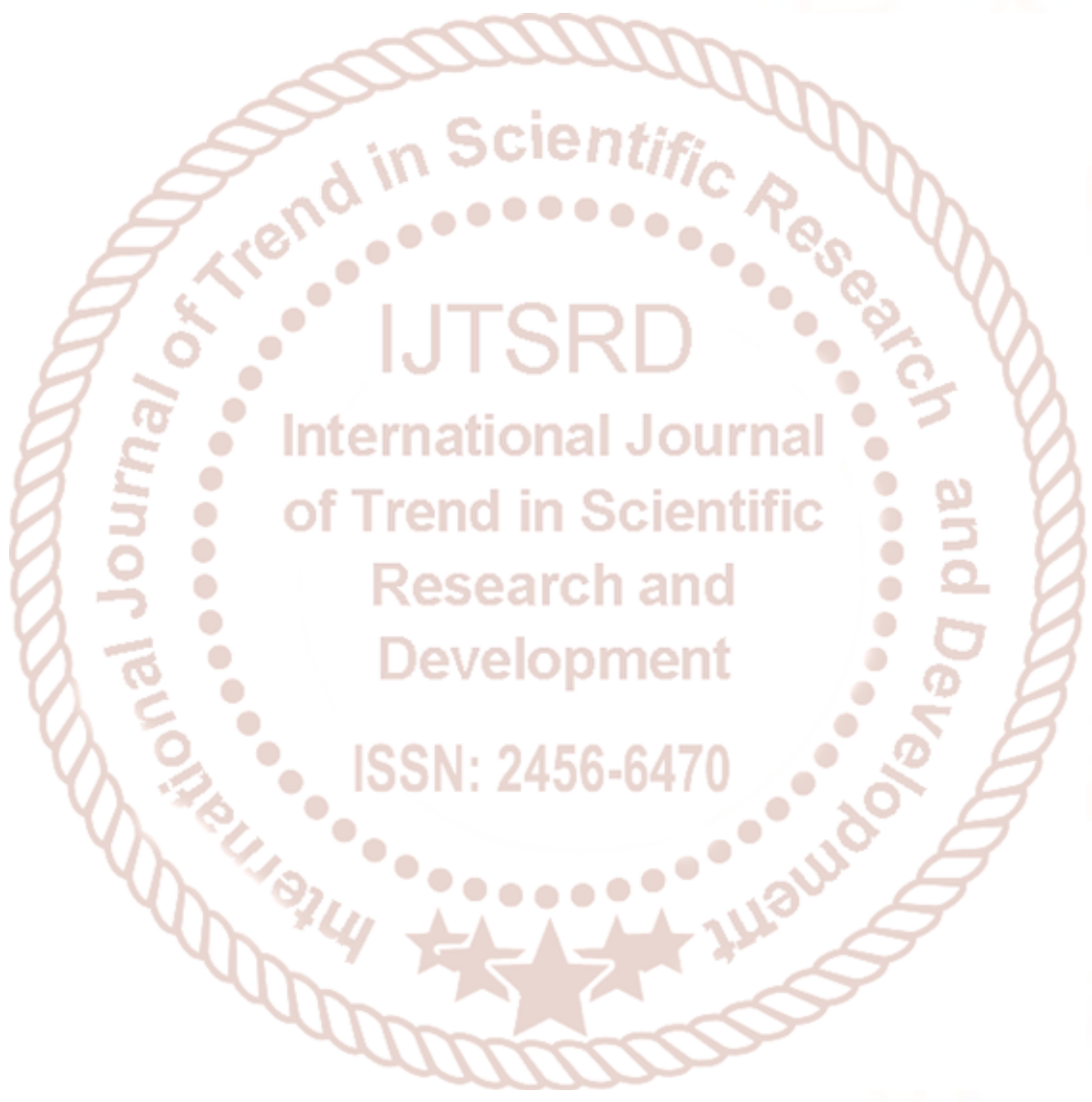

